was realized in "cruciform raised labyrinth" (CRL). The labyrinth installation was central square area $(1010 \mathrm{~cm})$ with four "corridors" (boards with width of $10 \mathrm{~cm}$ and length of $50 \mathrm{~cm}$ ) that moved off from every wall. Two of them oppositely placed "closed corridors" were limited on sides to walls that height of which was $40 \mathrm{~cm}$, two ones were "opened corridors" that were without any walls. The installation was raised at a height of $50 \mathrm{~cm}$ above floor level and was illuminated from one side by a lamp with power of $50 \mathrm{~W}$. A rat was placed on a central area so that their muzzles were against opened corridor. After that number of visits in closed and opened corridors and general time, that a rat was there, were registered. Every animal was been supervised for 5 minutes. On the $8^{\text {th }}$ day of the experiment method of conditioned reaction of passive avoidance was used: animals were tough in the installation that had light and dark compartments with electrode floor. The compartments were divided by partition with hole of a wire $4 \mathrm{~cm}$. in diameter stretch. Animal was placed in light compartment and after its movement in dark compartment; electric painful irritation was provoked by series of switching on current in electrode floor with power of $1,5 \mathrm{~mA}$ during $1 \mathrm{sec}$ in $2 \mathrm{sec}$. Thereby reflex of "dark compartment" was formed. Nootropic activity of test drug was estimated according to duration of latent period (safety of memorial track) up to animal's movement from light to dark compartment of installation in 1,3 and 7 twenty-four hours after teaching. In test
"Open field" rats, that were injected with test drugs in doses 100 and $300 \mathrm{mg} / \mathrm{kg}$, indexes of horizontal activity were higher in 1,6 and 1,5 times than check ones $(p \leq 0,05)$. On the contrary, indexes of vertical activities were lower and the number of defecation boluses was in 2,8 and 2,3 times lower than check ones $(p \leq 0,05)$. Index of explorative activity (holes) of animals of the $3^{\text {rd }}$ group was higher in 2,0 and 5,5 times than check indexes. Grooming indexes of animal of experimental groups was lower in 2,8 and 5,6 times $(p \leq 0,05)$. In the test КПЛ number of visits of experimental group rats in open parts of labyrinth was higher than check indexes in 1,2 and 1,3 times. General time of stay of rats, that were injected with test drugs in doses 100 and $300 \mathrm{mg} / \mathrm{kg}$, in open part was higher in 1,5 and 1,6 times $(p \leq 0,05)$ respectively than check indexes. Duration of latent period in test "conditioned reflex of passive avoidance" of animals that were injected with the drug in doses of 100 and $300 \mathrm{mg} / \mathrm{kg}$, for the $3^{\text {rd }}$ day of experiment was longer by 26 and $22 \%$ respectively than check index of check group rates, and for the $7^{\text {th }}$ day also it was longer by 24 and $21 \%$. Thereby, course intragastric injection of test drug in doses of 100 and $300 \mathrm{mg} / \mathrm{kg}$ increases horizontal and explorative activities of animals in test "Open field", moderately lowers level of anxiety: enlarge number of visits in light corridors of labyrinth and time that was spent there "CRL", improve indexes of memories in test "conditioned reflex of passive avoidance".

\title{
LIGNANS FROM SHIZANDRA CHINENSIS SEMINA OLEUM EXTRACT
}

\section{(C) Kosman V.M., Pozharitskaya O. N., Shikov A. N., Makarov V.G}

Saint-Petersburg Institute of Pharmacy, Russia

Schizandra chinensis Turcz. (Baill.), fam. Schizandraceae is endemic plant known for stimulation of physical activity and adaptogenic properties. Biological activity of Shizandra fruits and semina is caused by special group of chemical compounds - lignans (shizandrins, fig.).

They are lypophylic components and can be extracted by non-polar extragents. Oil extract from<smiles>COc1cc2c(c(OC)c1OC)-c1c(cc(OC)c(OC)c1OC)O[C@@H](C)[C@H](C)C2</smiles>

Shizandrol A<smiles>COc1cc2c(c(OC)c1OC)-c1c(cc3c(c1OC)OCO3)C[C@H](C)[C@H](C)C2</smiles>

Shizandrin B
Shisandra shinensis semina was obtained by original technology (1) with various fatty oils. The aim of the present work was to study lignans composition and content in Shisandra shinensis semina oil extracts. Qualitative and quantitative analysis was done by RP-HPLC method with standards of five shizandrins. Content of the dominant lignans was (in \%wt): shizandrol A 0,088-0,102, shizandrol B 0,075-0,087, shi-

Figure. Structures of main Shizandra lignans<smiles>COc1cc2c(c(OC)c1OC)-c1c(cc(OC)c(OC)c1OC)[C@H](C)[C@H](C)C2</smiles>

Shizandrin A<smiles>COc1cc2c(c(OC)c1OC)-c1c(cc3c(c1OC)OCO3)C[C@@H](C)[C@H](O)C2</smiles>

Shizandrol B 
zantherin A 0,021-0,024, shizandrin A 0,017-0,019, shizandrin B 0,074-0,095. Total content of shizandrins calculated in shizandrol A equivalents was about $0.3 \%$. Relations between individual lignans were about 1:1:0,2:0,2:1. This is optimal for adaptogenic properties of Shizandra drugs (2). Thus, fatty oils are effective for shizandra lignans extraction. The method was proposed for extract standardiza- tion and validated according to the $\mathrm{ICH}$ guidelines on the validation of analytical methods and (3).

References: (1) Shikov A. N., Pharm.Chem. J., 2006, 29: 385-388. (2) Panossian A., Wikman G.J., Ethnopharmacol., 2008, 118: 183212. (3) USP 32/NF 27. Validation of compendial procedures, 2009: 733-735.

\section{ANTIDIABETIC EFFECT OF UBIDECARENONE IN RATS}

\section{() Kovaleva M. A., Kokareva M. N., Makarova M. N., Makarov V. G.}

\section{Saint-Petersburg Institute of Pharmacy, Russia}

Diabetes mellitus is characterized by hyperglycemia, altered metabolism of lipids, carbohydrates and protein and an increased risk of complication of vascular diseases. Type 2 diabetes mellitus is characterized by derangement of insulin secretion and an inability of the peripheral tissues to respond to insulin. Antioxidant often been used for the treatment of diabetes and its complications. The purpose of the study was evaluation of antidiabetic activity of ubidecarenone, in the model of neonatal streptozotocin-induced diabetes on rats. Experiment was performed on rats-males and rats-female Wistar line. Diabetes was induced by a single dose intraperitoneally injection of streptozotocin $(60 \mathrm{mg} / \mathrm{kg})$ at 3 days postnatal. After 4 weeks the rats were orally administrated with ubidecarinon in starch slime at dose of $5.2 \mathrm{mg} / \mathrm{kg}$ (UC group); or starch slime (control group). Levels of glucose, body weight, total cholesterol, triglycerides were evaluated during the experiment. The ubidecarinone showed steady antidiabetic effect after
4 weeks of administration. Decrease level of blood glucose in $50 \%$ (rats-males) and $41 \%$ (rats- female) was obserwed. Results are present in the table:

\begin{tabular}{|l|c|c|}
\hline \multirow{2}{*}{ Group } & \multicolumn{2}{|c|}{ Blood glucose, mmol/l } \\
\cline { 2 - 3 } & Base line & After 4 weeks \\
\hline rats-males & $13,2 \pm 0,9$ \\
\hline Control $(n=6)$ & $12,8 \pm 1,1$ & $6,6 \pm 0,2^{*}$ \\
\hline UC $(n=6)$ & $11,6 \pm 1,3$ & $11,4 \pm 0,8$ \\
\hline rats- female & $9,4 \pm 0,7$ & $6,7 \pm 0,3^{*}$ \\
\hline Control $(n=6)$ & $10,7 \pm 0,9$ & \\
\hline UC $(n=6)$ & \multicolumn{3}{|c|}{$(p<0.05)$} \\
\hline *- significantly different from control group
\end{tabular}

Ubidecarinone effectively normalized metabolism in animals that was conformed by increased of glucose recycling by peripheral fabrics and displayed cytoprotective effect. Experiment data allow us to recommend ubidecarinone for further study, including clinical.

\section{THE APPROACH TO AN ANALYSIS OF TRACE ELEMENT STRUCTURE OF PLANTS}

\section{(C) Kruglov D. S.}

Novosibirsk State Medical University, Russia

Nowadays a lot researches are devoted to studying of herbs as sources of the essential trace elements. The number of elements defined by means of modern methods of masspectrometry, reaches 70 . There are two methods, which are used more often in the analysis of the amount of microelements. The first method is comparing of the elements which are contained in objects in extreme quantities. The second method is the establishment of the pair correlations between the separate elements. Both of these methods do not appear informative enough. The means of a data clustering have been applied which allow to analyze the set of all experimental data simultaneously. One of the most widely-used classes of methods involves hierarchical agglomerative clustering, in which two groups, chosen to optimize some criterion, are merged at each stage of the algorithm. The Ward's method was taken as a rule for association or communication of two groups into one cluster. The sum of root-mean-square deviations for any two (hypothetical) clusters which can be generated on each step must be minimized by this method. The distance between different clusters must be not less than a limit of variability of amount of the trace element the value of which was taken as $10 \%$. The aim of this work is the making of method which can be used for analysis of a lot data about con- 